\title{
Degradabilidade In Situ da Matéria Seca, Proteína Bruta e Fibra em Detergente Neutro do Capim-Furachão (Panicum repens, L.) Submetido à Adubação e em Diferentes Idades de Corte ${ }^{1}$
}

\section{Rogério da Silva Aguiar ${ }^{2}$, Hernán Maldonado Vásquez ${ }^{3}$, José Fernando Coelho da Silva 4}

RESUMO - O objetivo deste estudo foi avaliar as degradabilidades potencial e efetiva da matéria seca (MS), proteína bruta (PB) e fibra em detergente neutro (FDN) do capim-furachão (Panicum repens, L.) em diferentes idades de corte (15, 30, 45, 60 e 75 dias) sob presença ou ausência de adubação. As taxas de passagem das fases líquida e sólida da digesta foram também avaliadas. Cinco bovinos machos, 7/8 Holandês/Zebu, entre 30 e 36 meses de idade, com média de $545 \mathrm{~kg}$ PV foram distribuídos em delineamento em quadrado latino em esquema de subparcelas. As parcelas foram as cinco idades de corte; as subparcelas, os dois níveis de adubação; e as subsubparcelas, os seis tempos de incubação. Idade de corte, adubação, tempo de incubação e interações entre idade e adubação e entre tempo de incubação e adubação influenciaram a degradabilidade ruminal da MS, PB e FDN. A degradabilidade potencial da MS aumentou com o tempo de incubação. A adubação melhorou e as idades de corte reduziram a degradabilidade efetiva da MS, PB e FDN. As taxas de degradação da matéria seca variaram de 0,0481 a $0,0299 \mathrm{~h}^{-1}$.

Palavras-chave: adubação, capim-furachão, degradabilidade, idade de corte

\section{In Situ Degradabilities of Dry Matter, Crude Protein and Neutral Detergent Fiber of Furachão Grass (Panicum repens, L.) under Fertilization and Cutting Ages}

ABSTRACT - The objective of this study was to evaluate the potential and effective degradabilities of the dry matter (DM), crude protein (CP) and neutral detergent fiber (NDF) of furachão grass (Panicum repens, L) in different cutting ages (15, $30,45,60$ and 75 days) with the presence or absence of fertilization. The passage rates of liquid and solid digesta phases were also determined. Five male $7 / 8$ Holstein $x$ Zebu cattle from 30 to 36 months of age, with $545 \mathrm{~kg} \mathrm{LW}$ were allotted into a latin square design, in a split plot arrangement. The whole plot was the five cutting ages; the split plots, the two levels of fertilization; and the split split plots, the six incubation time. Cutting ages, fertilization, incubation times and the interactions between cutting ages and fertilization and between incubation time and fertilization affected the ruminal degradabilities of DM, PB and NDF. The potential DM degradability increased with the incubation time. The fertilization increased and cutting age decreased the effective degradabilities of DM, CP and NDF. The dry matter degradation rates ranged from .0481 to $.0299 \mathrm{~h}^{-1}$.

Key Words: fertilization, furachão grass, degradability, cutting age

\section{Introdução}

O estádio de crescimento do pasto é fator importante quando se pretende determinar a digestibilidade e o teor de proteína bruta da forrageira. Estudos desenvolvidos por ARMSTRONG (1982) mostraram que altas taxas de ganho de peso por animal são limitadas não somente pela baixa digestibilidade do material ingerido, como também pela quantidade de forragem disponível na pastagem. O manejo das pastagens torna-se importante, então, para que haja melhor utilização das forrageiras, pois estas, à medi- da que amadurecem, tendem a aumentar a quantidade da parede celular e diminuir sua digestibilidade, devido a sua mais rápida maturação e maior diversidade morfológica entre folhas e colmos (BARBI, 1991). O aumento na disponibilidade de forragem favorece o pastejo seletivo, com conseqüente aumento do consumo pelo animal, permitindo que maior produção por animal possa ser alcançada. Uma das principais formas de avaliação do valor nutritivo de forrageiras tropicais é o uso da técnica de degradabilidade in situ, uma vez que a parte solúvel da matéria seca da gramínea apresenta potencial-

\footnotetext{
${ }_{1}^{1}$ Parte da Dissertação de Mestrado apresentada pelo primeiro autor à Universidade Estadual do Norte Fluminense (UENF), Campos dos Goytacazes, RJ.

2 Zootecnista, UENF, MS em Produção Animal, CCTA, UENF.

3 Docente LZNA, CCTA, UENF - E-mail hernan@uenf.br

${ }^{4}$ Docente LZNA, CCTA, UENF, Av. Alberto Lamego 2000, 28015-620 Campos dos Goytacazes, RJ. Bolsista do CNPq.
} 
mente $100 \%$ de digestibilidade e a parede celular, potencial de degradação mais baixo (VAN SOEST,1967).

A técnica do saco de náilon contendo substratos incubados no rúmen para estudos de degradação da fibra não é nova. Atualmente esta técnica tem sido bastante utilizada e amplamente aceita em função de rapidez na sua execução, baixo custo e boa precisão dos resultados (GOMES, 1991). Além disso, diversos trabalhos têm utilizado esta técnica para medir o desaparecimento de componentes fibrosos e nitrogenados dos alimentos (ØRSKOV e McDONALD, 1979).

Estudando a degradabilidade ruminal de nove forrageiras em oito tempos de incubação, SINGH et al. (1989) encontraram variação de 5,3 a 24,2\% na degradabilidade da matéria seca, no tempo de 3 horas de fermentação ruminal, sendo que o maior aumento foi de 9,6 a 75,7\% entre os tempos 3 e 96 horas, respectivamente.

Com o objetivo de estimar as degradações ruminais efetivas da matéria seca, proteína bruta e fibra em detergente neutro do capim-elefante (Pennisetum purpureum Schum var. napier) em diferentes idades de corte, VIEIRA et al. (1996) concluíram que a altura da planta influenciou $(\mathrm{P}<0,05)$ a degradabilidade efetiva da MS e FDN, sendo máxima com, aproximadamente, $160 \mathrm{~cm}$ de altura entre 60 e 80 dias de crescimento. Por outro lado, BALSALOBRE et al. (1996), avaliando a digestibilidade in situ de amostras em um pastejo simulado de capim-elefante, concluíram que não houve diferença na digestibilidade da MS e FDN entre os períodos de coleta.

O objetivo do presente trabalho foi avaliar o efeito da adubação sobre as degradabilidades potenciais e efetivas da matéria seca, proteína bruta e fibra em detergente neutro do capim-furachão nas idades de corte de 15, 30, 45, 60 e 75 dias.

\section{Material e Métodos}

A incubação ruminal foi feita nas dependências do Colégio Agrícola Antônio Sarlo - Laboratório de Zootecnia e Nutrição Animal - UENF, utilizando-se bovinos machos $7 / 8$ Holandês/Zebu, com cânula ruminal, idade entre 30 e 36 meses e peso médio de $545 \mathrm{~kg}$.

O período de adaptação foi de 15 dias, durante o qual os animais foram alimentados com uma dieta composta de $75 \%$ de capim-elefante e $25 \%$ de feno de capim-colonião (Panicum maximum Jacq. Cv. Colonião), fornecidos duas vezes ao dia (às 8 e 17 h), tendo água e sal mineral à vontade. A proporção da mistura foi sendo modificada até atingir $100 \%$ de feno de capim-colonião.

Para a incubação ruminal utilizaram-se sacos de náilon de tamanho 14 x $6,5 \mathrm{~cm}$ e $50 \mu \mathrm{m}$ de abertura de poro, que foram identificados e levados a estufa a $105^{\circ} \mathrm{C}$ por uma noite, sendo pesados imediatamente. A seguir, foram colocados, em cada um dos sacos, 3,5 g de amostra moída em moinho com peneira $5 \mathrm{~mm}$, utilizando-se três repetições. Antes de serem incubados no rúmen, os sacos foram colocados em um balde com água morna por 10 minutos. Os tempos de incubação no rúmen foram $6,12,24,48$ e 72 horas, sendo que o tempo zero não foi incubado, mas colocado no mesmo balde e lavado em água corrente.

Em cada tempo de incubação, foram retirados seis sacos (três de cada tratamento) de cada animal e colocados em um balde com água fria por 10 minutos, com o objetivo de cessar a atividade microbiana. Em seguida, foram armazenados em congelador e, posteriormente, transportados ao laboratório para análise, onde foram exaustivamente lavados até que fossem removidas todas as partículas aderidas à superfície $\mathrm{e}$ obtida água de lavagem clara, sem material em suspensão. Logo após a lavagem, os sacos foram colocados, durante uma noite, em estufa $\left(85^{\circ} \mathrm{C}\right)$ com circulação forçada de ar e pesados ainda quentes.

A perda de peso observada na MS, PB e FDN, em cada tempo de incubação, foi considerada como degradabilidade potencial (Dp). Os dados foram ajustados por intermédio do modelo matemático: $\mathrm{Dp}=\mathrm{a}+\mathrm{b}\left(1-\mathrm{e}^{-\mathrm{ct}}\right)$, proposto por MEHREZ e ØRSKOV (1977), em que "Dp" é a quantidade de nutriente degradado no tempo "t"; "a", a fração rápidamente solúvel em água; "b", a fração insolúvel em água, mas potencialmente digestível; e "c", a taxa de degradação da fração "b".

Para o cálculo da degradabilidade efetiva (De), foi utilizada a equação de ØRSKOV e McDONALD (1979): $\mathrm{De}=\mathrm{a}+(\mathrm{bc}) / \mathrm{c}+\mathrm{k}$, em que $\mathrm{k}$ é a taxa de passagem.

Para se determinar a taxa de passagem da digesta pelo rúmen, foram utilizados dois indicadores externos, um de fase líquida, o Cobalto-EDTA, e um de fase sólida, o cromo mordante (ÚDEN et al., 1980).

Após o término do período de incubação ruminal e imediatamente antes do fornecimento do alimento, foram oferecidos, a três animais, em dose única, $5 \mathrm{~g}$ de Co-EDTA diluídos em $400 \mathrm{~mL}$ de água destilada introduzidas no rúmen, por meio da fístula ruminal, com auxílio de um funil acoplado a uma mangueira de borracha. 
A fibra mordantada foi colocada diretamente no rúmen na quantidade de $75 \mathrm{~g}$ por animal.

Amostras de $100 \mathrm{~mL}$ de fluido ruminal foram coletadas diretamente do rúmen nos tempos $0,2,4,6$, $8,12,24,30,36,48$, e 72 horas, após a colocação do indicador no rúmen, filtradas em gaze de algodão e acondicionadas em frascos de vidro, que foram colocados no congelador para posterior determinação da concentração de Co.

As amostras de sólidos ruminais foram coletadas, nos mesmos tempos utilizados para amostras de líquido ruminal, na porção medial do rúmen, em quantidade de aproximadamente $100 \mathrm{~g}$, sendo colocadas, a seguir, para secar em estufa a $60^{\circ} \mathrm{C}$ por 72 horas. Posteriormente foram moídas em moinhos com peneiras de $1 \mathrm{~mm}$ e acondicionadas em frascos de vidros.

O líquido ruminal foi centrifugado a $10.000 \mathrm{rpm}$ durante 15 minutos e, posteriormente, o sobrenadante foi levado para dosagem de Co no espectrofotomêtro de absorção atômica.

O preparo das amostras e as determinações de matéria seca $(\mathrm{MS})$, proteína bruta $(\mathrm{PB})$, fibra em detergente neutro (FDN) e cromo ( $\mathrm{Cr}$ ) foram feitas conforme descritas por SILVA (1990).

Para se calcular as taxas de passagem de partículas e de líquido ruminal, utilizou-se regressão linear entre os tempos de coleta das amostras e o logaritmo natural das concentrações dos indicadores, em que as taxas de passagens foram consideradas como os coeficientes de inclinação (b) das equações de regressão, pois a diluição do cromo e do cobalto no rúmen tem comportamento que pode ser representado por uma função logarítmica, conforme descrito por GOMES (1991).

O delineamento experimental foi em quadrados latinos, montado em estrutura de parcelas subdivididas, sendo as análises estatísticas realizadas de acordo com o seguinte modelo:

$$
\begin{gathered}
Y_{j k l m n}=\mu+L_{i}+C_{j}+I_{k}+\varepsilon_{i j k}+A_{d l}+(I x A d)_{k l}+ \\
\varepsilon_{i j k l}+T_{m}+(I x T)_{k m}+(A l x T)_{l m}+(I x A d x T)_{k l m}+\varepsilon_{i j k l m n} \\
\text { em que } \\
Y_{j k l m n}=\text { observação relativa a linha (i) na coluna }
\end{gathered}
$$
$(j)$, adubação $(l)$ no tempo $(t)$, nas respectivas interações e na repetição n;

$$
\begin{aligned}
\mu & =\text { média geral; } \\
L_{i} & =\text { efeito da linha } \mathrm{i} \text { (período); } \\
C_{j} & =\text { efeito da coluna } \mathrm{j} \text { (animal); } \\
I_{k} & =\text { efeito do nível } \mathrm{k} \text { do fator idade de corte; } \\
\varepsilon_{i j k} & =\text { erro experimental da parcela; } \\
A_{d l} & =\text { efeito do nível l do fator Ad (adubação); } \\
(I x A d)_{k 1} & =\text { efeito da interação fator I com do fator Ad; }
\end{aligned}
$$

$\varepsilon_{i j k l} \quad=$ erro experimental da subparcela;

$T_{m} \quad=$ efeito do nível $\mathrm{m}$ do fator $\mathrm{T}$ (tempo de incubação);

$(I x T)_{k m}=$ efeito da interação do fator I com o fator $\mathrm{T}$;

$(A D x T)_{l m}=$ efeito da interação do fator Ad com fator $\mathrm{T}$;

$(\operatorname{IxAdxT})_{\mathrm{klj}}=$ efeito da interação do fator I com o fator Ad e com o fator T; e

$$
\varepsilon_{i j k l m n}=\text { erro experimental relativo a }
$$
subsubparcela.

Foi realizada aleatorização entre os cinco animais e as cinco idades de corte da gramínea, sendo que, em cada período, foram incubadas em cada animal amostras de determinada idade de corte, sendo: $\mathrm{T} 1=15$ dias com adubo, $\mathrm{T} 2=30$ dias com adubo, $\mathrm{T} 3=45$ dias com adubo, $\mathrm{T} 4=60$ dias com adubo, $\mathrm{T} 5=75$ dias com adubo, $\mathrm{T} 6=15$ dias sem adubo, $\mathrm{T} 7=30$ dias sem adubo, $\mathrm{T} 8=45$ dias sem adubo, $\mathrm{T} 9=60$ dias sem adubo e $\mathrm{T} 10=75$ dias sem adubo. Assim, todos os tratamentos foram incubados em todos os animais em diferentes períodos (Tabela 1).

Alocaram-se as cinco idades de corte $(15,30,45$, 60 e 75 dias) nas parcelas principais; os níveis de adubação (adubado e não adubado), na sub parcela; e os tempos de incubação, na sub sub parcelas.

Os resultados foram interpretados, estatisticamente, por meio de análises de variância e regressão. As variáveis da equação da degradabilidade potencial foram analisadas pelo modelo não-linear e as médias do fator qualitativo foram comparadas pelo teste Tukey, em nível de 5\% de probabilidade. Todos os cálculos foram realizados utilizando o Statistical Analysis System (SAS, 1989).

Tabela 1 - Esquema usado para incubação ruminal das amostras dos diferentes tratamentos

Table 1 - Scheme used for the ruminal samples incubation of the different treatments

\begin{tabular}{lccccc}
\hline \multirow{2}{*}{ Animal } & \multicolumn{5}{c}{$\begin{array}{c}\text { Período } \\
\text { Period }\end{array}$} \\
\cline { 2 - 6 } & 1 & 2 & 3 & 4 & 5 \\
\hline A & T1T6 & T2T7 & T3T8 & T4T9 & T5T10 \\
B & T2T7 & T3T8 & T4T9 & T5T10 & T1T6 \\
C & T3T8 & T4T9 & T5T10 & T1T6 & T2T7 \\
D & T4T9 & T5T10 & T1T6 & T2T7 & T3T8 \\
E & T5T10 & T1T6 & T2T7 & T3T8 & T4T9 \\
\hline
\end{tabular}


AGUIAR et al.

Tabela 2 - Análises de variância da degradabilidade ruminal da matéria seca (MS), proteína bruta (PB) e fibra em detergente neutro (FDN) do capim-furachão

Table 2 - Analyses of variance for dry matter (DM), crude protein (CP) and neutral detergent fiber (NDF) ruminal degradability of furachão grass

\begin{tabular}{|c|c|c|c|c|}
\hline $\begin{array}{l}\text { Fonte de variação } \\
\text { Source of variation }\end{array}$ & $\begin{array}{l}\mathrm{gl} \\
d f\end{array}$ & $\begin{array}{l}\text { MS } \\
D M\end{array}$ & $\begin{array}{l}\mathrm{PB} \\
C P\end{array}$ & $\begin{array}{l}\text { FDN } \\
N D F\end{array}$ \\
\hline$\overline{P e r i ́ o d o ~(l i n h a) ~}$ & 4 & $*$ & $*$ & $*$ \\
\hline Period (row) & & & & \\
\hline $\begin{array}{l}\text { Animal (coluna) } \\
\text { Animal (column) }\end{array}$ & 4 & * & $*$ & * \\
\hline Idade de corte (I) & 4 & * & * & * \\
\hline $\begin{array}{l}\text { Cutting age } \\
\text { Erro a }\end{array}$ & 12 & & & \\
\hline $\begin{array}{l}\text { Error a } \\
\text { Adubo (Ad) }\end{array}$ & 1 & $*$ & $*$ & \\
\hline $\begin{array}{l}\text { Fertilizer } \\
\text { AdxI }\end{array}$ & 4 & $*$ & $*$ & $*$ \\
\hline $\begin{array}{l}\text { Erro b } \\
\text { Error b }\end{array}$ & 20 & & & \\
\hline $\begin{array}{l}\text { Tempo de incubação }(\mathrm{T}) \\
\text { Incubation time }\end{array}$ & 5 & $*$ & $*$ & $*$ \\
\hline IxT & 20 & * & * & * \\
\hline AdxT & 5 & & & \\
\hline AdxIxT & 20 & & & \\
\hline $\begin{array}{l}\text { Erro total } \\
\text { Total error }\end{array}$ & 200 & & & \\
\hline$\overline{\mathrm{CV}}$ & & 8,646 & 8,558 & 15,35 \\
\hline
\end{tabular}

* Significativo $(P<0,05)$, pelo test $F$.

* Significant $(P<.05)$ by $F$ test.

\section{Resultados e Discussão}

\section{Degradabilidade}

A análise de variância (Tabela 2) permite verificar que houve efeito $(\mathrm{P}<0,05)$ do animal, da idade de corte, da adubação, do tempo de incubação e das interações entre idade de corte e adubação e entre tempo e idade de corte, para as degradabilidades da matéria seca (MS), proteína bruta (PB) e fibra em detergente neutro (FDN) do capim-furachão. As porcentagens da degradação da MS do capimfurachão, em função dos tempos de incubação no rúmen, presença ou ausência de adubação, e as estimativas dos coeficientes "a", "b" e "c" das equações ajustadas para as degradabilidades potenciais da MS do capim-furachão contam da Tabela 3. A degradabilidade potencial (Dp) aumentou $(\mathrm{P}<0,05)$ em função do tempo de incubação e diminuiu $(\mathrm{P}<0,05)$ em função da idade de corte.

Aos 60 dias de idade, com 24 horas de incubação, as porcentagens dos resíduos da degradação ruminal foram 44,69 e 43,81\%, respectivamente, para com e sem adubação. BARBI (1991), aos 56 dias de idade e também com 24 horas de incubação, encontrou valores de 51,$7 ; 48,6 ; 60$; e 55,8\%, respectivamente, para a degradabilidade dos capins andropogon (Andropogon gayanus Kunth), tobiatã (Panicum maximum Jacq. cv. Tobiatã), cameroon (Pennisetum purpureum, Schum. cv. cameroon) e jaraguá (Hyparrhenia rufa Ness.).

A Dp obtida aos 60 dias de idade de corte foi 63,73 e $65,14 \%$, respectivamente, para o capim com e sem adubação. Estes valores foram inferiores aos encontrados por BERGAMASCHINE et al. (1994), que encontraram 81,$20 ; 80,60 ; 75,10$; e $68 \%$ respectivamente, para as gramíneas setária (Setaria anceps Stapf ex Massey), jaraguá, pangola (Digitaria decumbens Stent.) e grama-estrela (Cynodon nlemfuensis Vanderyst var. nlemfuensis). Provavelmente, a menor Dp observada no presente experimento tenha ocorrido em função do efeito da dieta consumida pelos animais fistulados, pois VILELA(1994), em um estudo de degradabilidade de vários alimentos em vacas alimentadas com diferentes rações, encontrou interação $(\mathrm{P}<0,05)$ entre as rações oferecidas aos animais e os alimentos incubados no rúmen, concluindo que a degradação de cada alimento pode ser influenciada pela ração ou que, para a mesma ração, ocorrem diferenças nas degradabilidades entre os alimentos.

Como pode ser observado na Tabela 4, a adubação melhorou $(\mathrm{P}<0,05)$ a $\mathrm{Dp}$ da $\mathrm{MS}$, pois os valores da degradabilidade e dos parâmetros da equação foram maiores para as amostras do capim adubado. 
Rev. bras. zootec.

Tabela 3 - Porcentagem da degradação ruminal e estimativa dos coeficientes a, b e c das equações ajustadas para a degradabilidade da matéria seca do capim-furachão com ou sem adubo

Table 3 - Percentage of the ruminal degradation and estimate of $a, b$, and c coefficients from the adjusted equations for dry matter degradability of furachão grass with or without fertilization

Idade de corte (dias) Tempo de incubação (h.)

Cutting age (days)

Incubation time

Incubation time

\begin{tabular}{|c|c|c|c|c|c|c|c|c|c|c|}
\hline \multirow{2}{*}{ 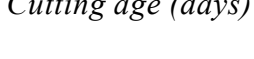 } & \multicolumn{6}{|c|}{ 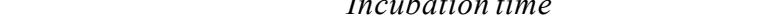 } & \multicolumn{3}{|c|}{ Lquatem partamerer } & \multirow[b]{2}{*}{$r^{2}$} \\
\hline & 0 & 6 & 12 & 24 & 48 & 72 & $\mathrm{a}$ & $\mathrm{b}$ & $\mathrm{c}$ & \\
\hline & \multicolumn{10}{|c|}{$\begin{array}{c}\text { Degradabilidade potencial com adubação (\%) } \\
\text { Potential degradability with fertilization }\end{array}$} \\
\hline 15 & 15,49 & 26,89 & 41,03 & 58,08 & 68,66 & 73,40 & 0,1411 & 0,6132 & 0,0481 & 0,9914 \\
\hline 30 & 15,46 & 26,30 & 37,45 & 49,94 & 64,06 & 68,67 & 0,1510 & 0,5704 & 0,0398 & 0,9916 \\
\hline 45 & 14,19 & 22,75 & 33,04 & 48,05 & 59,99 & 65,53 & 0,1309 & 0,5653 & 0,0374 & 0,9915 \\
\hline 60 & 12,08 & 23,17 & 32,11 & 44,69 & 55,26 & 61,55 & 0,1215 & 0,5158 & 0,0404 & 0,9887 \\
\hline \multirow[t]{2}{*}{75} & 14,02 & 21,12 & 29,09 & 40,22 & 5385 & 59,11 & 0,1340 & 0,5219 & 0,0299 & 0,9928 \\
\hline & \multicolumn{10}{|c|}{ Degradabilidade potencial sem adubação (\%) } \\
\hline 15 & 13,84 & 23,73 & 35,31 & 52,93 & 64,82 & 70,74 & 0,1249 & 0,6183 & 0,0402 & 0,9931 \\
\hline 30 & 12,48 & 25,43 & 36,63 & 47,88 & 62,53 & 66,59 & 0,1269 & 0,5655 & 0,0429 & 0,9920 \\
\hline 45 & 13,39 & 21,61 & 31,44 & 45,08 & 57,81 & 63,95 & 0,1254 & 0,5625 & 0,0344 & 0,9932 \\
\hline 60 & 15,42 & 24,60 & 33,31 & 43,81 & 55,98 & 60,79 & 0,1531 & 0,4893 & 0,0369 & 0,9887 \\
\hline 75 & 13,30 & 20,82 & 29,23 & 42,86 & 54,42 & 60,86 & 0,1246 & 0,5350 & 0,0327 & 0,9944 \\
\hline
\end{tabular}

Degradabilidade potencial com adubação (\%)

Equation paramet

Tabela 4 - Degradabilidade efetiva da matéria seca, estimada para as taxas de passagem de 0,02; 0,0416; e 0,08 $\mathrm{h}^{-1}$, do capim-furachão com ou sem adubação

Table 4 - Effective dry matter degradability, estimated for digesta passage rates of .02, .0416, and .08 $h^{-1}$, of furachão grass with or without fertilization

Idade de corte (dias)

Cutting ages (days)
Taxa de passagem $\left(\mathrm{h}^{-1}\right)$

Passage rate

\begin{tabular}{lcc}
\multicolumn{3}{c}{ Passage rate } \\
\hline 0,02 & 0,0416 & 0,08 \\
\hline \multicolumn{3}{c}{$\begin{array}{c}\text { Com adubo } \\
\text { Fertilization }\end{array}$} \\
\hline 0,57 & 0,47 & 0,37 \\
0,53 & 0,43 & 0,34 \\
0,50 & 0,40 & 0,31 \\
0,47 & 0,38 & 0,29 \\
0,45 & 0,35 & 0,28
\end{tabular}

Sem adubação

Without fertilization

\begin{tabular}{lll}
\hline 0,54 & 0,43 & 0,33 \\
0,51 & 0,41 & 0,32 \\
0,48 & 0,38 & 0,29 \\
0,47 & 0,38 & 0,31 \\
0,46 & 0,36 & 0,28 \\
\hline
\end{tabular}

Pode-se concluir, então, que a adubação pode ter proporcionado aumento na relação folha:haste, tornando o material menos fibroso e, assim, melhorando a degradabilidade.

As taxas de passagem das fases líquida e sólida da digesta ruminal encontradas neste trabalho, quando os animais foram alimentados com feno de capim-colonião, foram 4,7 e $1,35 \% / h$, respectivamente. $\mathrm{O}$ valor encontrado para taxa de passagem de sólidos ficou abaixo do nível estimado para animais em mantença, que é de 2,0\%/h (AFRC, 1993), subestimando o valor nutritivo do capim em estudo. Este fato pode ter ocorrido em função da qualidade do feno de capim-colonião fornecido aos animais durante o período experimental.

$\mathrm{Na}$ Tabela 4, encontram-se os valores da degradabilidade efetiva (De) da matéria seca, em função das idades de corte, estimadas para as taxas de passagem de $2 ; 4,16$; e $8 \% / \mathrm{h}$. O valor da taxa de passagem de $4,16 \% / \mathrm{h}$ é um valor teórico, estimado em 24 horas de incubação ruminal (Cerda et al., 1989, citados por BARBI, 1991). 
O valor médio de $38 \%$ para a De da matéria seca, aos 60 dias de idade, para a taxa de passagem de $0,0416 \mathrm{~h}^{-1}$ encontrada neste trabalho, foi semelhante aos descritos por BERGAMASCHINE et al. (1994), em estudo de degradabilidade in situ com gramíneas do gênero Brachiaria, ou seja: $38,50 \%$ para $B$. decumbens, $37,10 \%$ para B.brizantha e $35,60 \%$ para B. humidícola. Esses autores encontraram 35,4; 39,4 ; e $37,2 \%$, respectivamente, para os capins colonião, andropógon e elefante.

$\mathrm{Na}$ Tabela 5 encontram-se os valores dos coeficientes "a", "b" e "c" das equações ajustadas para as Dp da proteína bruta, em função dos tempos de incubação, e para os tratamentos com e sem adubo. Os valores estimados para a fração "a" encontrados neste trabalho são maiores que os encontrados por MALAFAIA et al. (1997) de 17,38; 19,33 e 11,58\%, para os capins tifton (Cynodon spp.), elefante e Brachiaria brizanta aos 60 dias de idade de corte, respectivamente. Isto se explica em virtude do valor da fração solúvel em água apresentado pelo capimfurachão. Esses autores encontraram para $B$. decumbens na mesma idade $32,28 \%$ para a fração "a", que foi semelhante à deste trabalho (Tabela 5). Já VILELA (1994) encontrou valor de 25,29\% para fração "a" em capim-elefante, enquanto RIBEIRO et al. (1994), trabalhando com três gramíneas nativas do Rio Grande do Sul, encontraram valores de "a" na ordem de 23,55; 17,72; e 17,85\% para $P$. notatum, $A$. lateralis e $A$. jubata, respectivamente.

O valor do parâmetro "b" estimado neste trabalho para degradabilidade potencial da PB do capim aos 60 dias de idade, com e sem adubo (Tabela 5), é menor que o descrito pelo AFRC (1993) de 0,57\%, em média, para gramíneas com 55 a 60 dias de idade.

A adubação aumentou $(\mathrm{P}<0,05)$ a porcentagem da Dp da PB. Pode-se inferir que aos 15, 30 e 60 dias de idade os valores médios da degradabilidade foram superiores para as amostras do capim adubado e, à medida que aumentou a idade da planta, a degradabilidade diminuiu (Tabela 6).

$\mathrm{Na}$ Tabela 7, encontram-se os valores das De da proteína bruta estimadas para as taxas de passagem de 2; 4,16; e 8\%/h. Os valores da De da PB para a taxa de passagem de $4,16 \% / \mathrm{h}$ aos 60 dias, com ou sem adubação, encontrados neste trabalho, foram maiores que os descritos por BERGAMASCHINE (1994), de 33; 23; 44; 43,40;30;31,60;25,70; e $37,70 \%$ para os capins setária, jaraguá, pangola, grama-estrela, B.decumbens, B.brizantha, B.humidicola e B.ruziziensis, respectivamente.

Os coeficientes "a", "b" e "c" das equações, ajustadas para as degradabilidades potenciais da fibra em detergente neutro, em função dos tempos de incubação, para os tratamentos com e sem adubo, encontram-se na Tabela 8. Em todas as idades de corte e na presença ou ausência de adubação, a fração solúvel da FDN medida no tempo zero encontradas neste trabalho foram próximas de zero. Portanto, assumiu-se, o valor zero para todas as idades. Os valores dos parâmetros "b" e "c" que determinam, respectivamente, a fração potencial-

Tabela 5 - Porcentagem da degradação ruminal e estimativa dos coeficientes a, b, c das equações ajustadas para a degradabilidade da proteína bruta do capim-furachão ( $P$. repens. $L$ ) com ou sem adubo

Table 5 - Percentage of ruminal degradation and estimate of $a, b$, and c coefficients of the adjusted equations for crude protein degradability of furachão grass (P. repens, $L$ ) with or without fertilization

Idade de corte (dias) Tempo de incubação (horas)

Cutting age (days) Incubation time (hours)

Parâmetro da equação

Parameter of equation

\begin{tabular}{|c|c|c|c|c|c|c|c|c|c|c|}
\hline & 0 & 6 & 12 & 24 & 48 & 72 & $\mathrm{a}$ & $\mathrm{b}$ & $\mathrm{c}$ & $r^{2}$ \\
\hline & \multicolumn{10}{|c|}{$\begin{array}{c}\text { Degradabilidade potencial com adubação (\%) } \\
\text { Potential degradability with fertilized }\end{array}$} \\
\hline 15 & 38,61 & 50,65 & 58,76 & 63,96 & 82,48 & 85,74 & 0,3861 & 0,4918 & 0,0454 & 0,9956 \\
\hline 30 & 28,31 & 38,41 & 49,11 & 59,78 & 74,40 & 80,24 & 0,2831 & 0,5622 & 0,0355 & 0,9967 \\
\hline 45 & 22,73 & 33,29 & 41,08 & 56,66 & 71,38 & 76,25 & 0,2273 & 0,5934 & 0,0344 & 0,9951 \\
\hline 60 & 34,24 & 40,75 & 47,19 & 56,42 & 66,83 & 73,91 & 0,3424 & 0,4600 & 0,0267 & 0,9908 \\
\hline \multirow{2}{*}{75} & 30,68 & 38,74 & 42,99 & 51,80 & 65,75 & 67,46 & 0,3068 & 0,4255 & 0,0307 & 0,9832 \\
\hline & \multicolumn{10}{|c|}{$\begin{array}{c}\text { Degradabilidade potencial sem adubação (\%) } \\
\text { Potential degradability without fertilized }\end{array}$} \\
\hline 15 & 31,98 & 44,53 & 51,15 & 58,64 & 74,39 & 80,55 & 0,3198 & 0,5105 & 0,0419 & 0,9942 \\
\hline 30 & 27,30 & 32,87 & 44,78 & 54,71 & 71,17 & 77,02 & 0,2730 & 0,5934 & 0,0344 & 0,9951 \\
\hline 45 & 26,63 & 35,44 & 43,50 & 54,32 & 67,41 & 73,78 & 0,2663 & 0,5253 & 0,0314 & 0,9897 \\
\hline 60 & 33,15 & 37,52 & 43,42 & 47,66 & 60,58 & 65,38 & 0,3315 & 0,4349 & 0,0193 & 0,9735 \\
\hline 75 & 30,43 & 37,37 & 42,53 & 51,74 & 63,07 & 68,38 & 0,3043 & 0,4421 & 0,0274 & 0,9873 \\
\hline
\end{tabular}


Rev. bras. zootec.

Tabela 6 - Efeito da adubação sobre as médias de degradabilidade potencial da proteína bruta (\%), em função da idade de corte do capim-furachão

Table 6 - Effect of fertilization on potential crude protein degradability means (\%) by cutting ages of furachão grass

Idade de corte (dias) $\quad$ Com adubação $\quad$ Sem adubação

Cutting age (days) Fertilization Withoutfertilization

\begin{tabular}{lll}
\hline 15 & $0,6545^{\mathrm{a}}$ & $0,5810^{\mathrm{b}}$ \\
30 & $0,5504^{\mathrm{a}}$ & $0,5130^{\mathrm{b}}$ \\
45 & $0,5023^{\mathrm{a}}$ & $0,5018^{\mathrm{a}}$ \\
60 & $0,5322^{\mathrm{a}}$ & $0,4795^{\mathrm{b}}$ \\
75 & $0,4956^{\mathrm{a}}$ & $0,4892^{\mathrm{a}}$ \\
\hline
\end{tabular}

Médias, na linha, seguidas por letras diferentes são diferentes $(P<0,05)$ pelo teste Tukey.

Means, within a row, followed by different letters are different $(P<.05)$ by Tukey test. mente degradável no rúmen e a taxa de degradação foram maiores para o capim adubado $(\mathrm{P}<0,05)$ aos 15,30 e 60 dias de idade.

Conclui-se, então, que a adubação proporcionou melhor condição de crescimento do capim, aumentando a produção, melhorando a composição dos componentes da parede celular, tornando-o menos fibroso, favorecendo as condições ao ataque microbiano e, conseqüentemente, aumentando a degradabilidade potencial, como pode ser observado na Tabela 9 .

Os valores de De da FDN, em função das idades de corte, encontram-se na Tabela 10. Pode-se observar que os valores da De diminuíram em função do

Tabela 7 - Degradabilidade efetiva da proteína bruta, estimada para as taxas de passagem de 0,02; 0,0416; e $0,08 \mathrm{~h}^{-1}$, do capim-furachão com ou sem adubação

Table 7 - Effective crude protein degradability, estimated for digesta passage rates of $.02, .0416$, and .08 $h^{-1}$, of furachão grass with or without fertilization

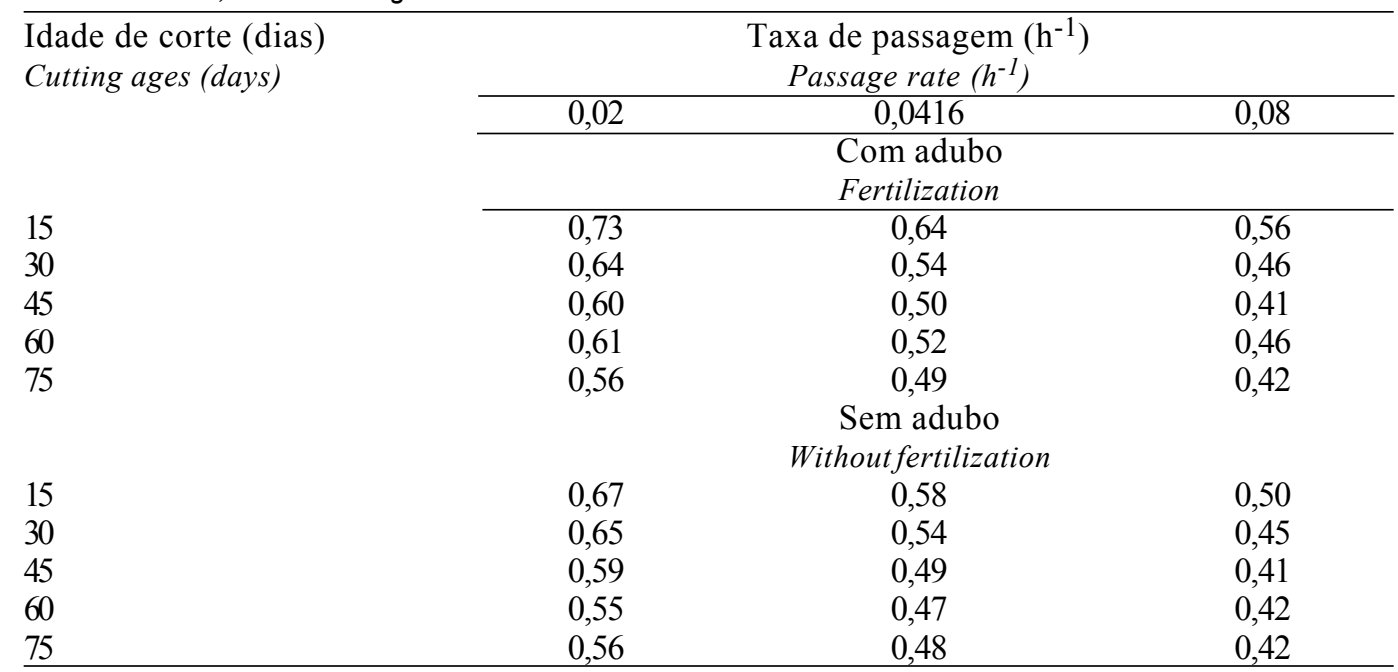

Tabela 8 - Porcentagem da degradação ruminal e estimativa dos coeficientes a, b, c das equações ajustadas para a degradabilidade da fibra em detergente neutro (FDN) do capim-furachão com ou sem adubação

Table 8 - Percentage of ruminal degradation and estimate of $a, b$, and c coefficients of the adjusted equations for neutral detergent fiber degradability of furachão grass with or without fertilization

\begin{tabular}{|c|c|c|c|c|c|c|c|c|c|c|}
\hline \multirow[t]{2}{*}{$\begin{array}{l}\text { Idade de corte (dias } \\
\text { Cutting age (days) }\end{array}$} & \multirow[b]{2}{*}{0} & \multicolumn{5}{|c|}{$\begin{array}{l}\text { Tempo de incubação }(\mathrm{h}) \\
\text { Incubation time }\end{array}$} & \multicolumn{3}{|c|}{$\begin{array}{l}\text { Parâmetro da equação } \\
\text { Parameter of equation }\end{array}$} & \multirow[b]{2}{*}{$r^{2}$} \\
\hline & & 6 & 12 & 24 & 48 & 72 & $\mathrm{a}$ & $\mathrm{b}$ & $\mathrm{c}$ & \\
\hline & \multicolumn{10}{|c|}{$\begin{array}{c}\text { Degradabilidade potencial com adubação (\%) } \\
\text { Potential degradability with fertilization }\end{array}$} \\
\hline 15 & 0 & 10,24 & 29,96 & 51,23 & 65,32 & 70,98 &,- 0276 & 0,7746 & 0,0447 & 0,9844 \\
\hline 30 & 0 & 7,42 & 22,11 & 39,67 & 58,37 & 63,87 &,- 0235 & 0,7413 & 0,0334 & 0,9733 \\
\hline 45 & 0 & 5,37 & 19,65 & 39,44 & 54,57 & 61,27 &,- 0304 & 0,7170 & 0,0333 & 0,9784 \\
\hline 60 & 0 & 3,19 & 14,91 & 34,42 & 46,15 & 55,03 &,- 0280 & 0,6811 & 0,0267 & 0,9622 \\
\hline 75 & 0 & 1,56 & 12,64 & 29,47 & 47,34 & 54,34 &,- 0352 & 0,7310 & 0,0231 & 0,9810 \\
\hline & \multicolumn{10}{|c|}{$\begin{array}{c}\text { Degradabilidade potencial sem adubação (\%) } \\
\text { Potential degradability withoutfertilization }\end{array}$} \\
\hline 15 & 0 & 5,80 & 23,03 & 45,39 & 60,95 & 68,00 &,- 0361 & 0,7853 & 0,0357 & 0,9820 \\
\hline 30 & 0 & 5,20 & 20,64 & 35,51 & 55,60 & 60,65 &,- 0262 & 0,7274 & 0,0306 & 0,9676 \\
\hline 45 & 0 & 7,66 & 21,02 & 38,63 & 54,69 & 61,82 &,- 0196 & 0,7076 & 0,0332 & 0,9876 \\
\hline 60 & 0 & 9,84 & 19,72 & 33,62 & 48,75 & 55,28 &,- 0048 & 0,6163 & 0,0331 & 0,9704 \\
\hline 75 & 0 & 1,59 & 11,79 & 31,11 & 46,79 & 55,17 &,- 0367 & 0,7364 & 0,0232 & 0,9821 \\
\hline
\end{tabular}


828

Tabela 9 - Efeito da adubação sobre as médias de degradabilidade potencial (\%) da fibra em detergente neutro, em função da idade de corte do capim-furachão

Table 9 - Effect of fertilization on neutral detergent fiber potential degradability means (\%) by cutting ages of furachão grass

Idade de corte (dias) Com adubação Sem adubação

Cutting age (days) With fertilization Without fertilization

$150,3567^{\mathrm{a}} \quad 0,3090^{\mathrm{b}}$

30

45

60

$0,3018^{\mathrm{a}}$

$0,2777^{b}$

$0,2920^{\mathrm{a}} \quad 0,2773^{\mathrm{a}}$

$0,2752^{\mathrm{a}} \quad 0,2338^{\mathrm{b}}$

$75 \quad 0,2213^{\mathrm{a}} \quad 0,2209^{\mathrm{a}}$

Médias, na linha, seguidas por letras diferentes são diferentes pelo teste Tukey $(\mathrm{P}<0,05)$.

Means, within a row, followed by different letters are different by Tukey test $(P<.05)$.
AGUIAR et al.

aumento da idade de corte, fato decorrente do amadurecimento da forragem, que lhe confere maior teor de parede celular. A De diminuiu com o aumento da taxa de passagem, sendo observados menores valores da De para o capim sem adubação.

Para a taxa de passagem de $0,0416 \mathrm{~h}^{-1}$, encontrou-se o valor médio de $27 \%$, para a De da FDN, superior ao descrito por TEIXEIRA et al. (1996), que trabalharam com napier (Pennisetum purpureum Schum var. napier) e encontraram valores entre 16,2 e $19,1 \%$. No mesmo trabalho, esses autores encontraram para o FDN da B.brizantha De de 30,6\%.

Tabela 10 - Degradabilidade efetiva da fibra em detergente neutro, estimada para as taxas de passagem de 0,02; 0,0416; e $0,08 \mathrm{~h}^{-1}$, do capim-furachão, com ou sem adubação

Table 10 - Effective neutral detergent fiber degradability, estimated for digesta passage rates of .02, .0416 and .08 $\mathrm{h}^{-1}$, of furachão grass with or without of fertilization

Idade de corte (dias)

Cutting age (days)

15

30

45

60

75

30

45

60

75

\begin{tabular}{ccc}
\multicolumn{3}{c}{$\begin{array}{c}\text { Taxa de passagem }\left(\mathrm{h}^{-1}\right) \\
\text { Passage rate }\left(h^{-1}\right)\end{array}$} \\
\hline 0,02 & 0,0416 & 0,08 \\
\hline \multicolumn{3}{c}{ Com adubação } \\
Fertilization \\
\hline 0,52 & 0,39 & 0,28 \\
0,46 & 0,33 & 0,23 \\
0,44 & 0,31 & 0,22 \\
0,39 & 0,26 & 0,17 \\
0,38 & 0,24 & 0,16
\end{tabular}

Sem adubação

Withoutfertilization

$0,35 \quad 0,24$

$0,30-0,21$

$0,31 \quad 0,21$

$0,28 \quad 0,21$

$0,21 \quad 0,15$

\section{Conclusões}

O potencial de degradação ruminal da MS, PB e FDN do capim-furachão variou com a idade de corte e a adubação.

A degradabilidade potencial da matéria seca aumentou em função do tempo de incubação.

A adubação melhorou a degradabilidade efetiva da matéria seca, proteína bruta e fibra em detergente neutro, as quais foram reduzidas com o aumento na idade do capim.

As taxas de degradação da matéria seca decresceram, de 15 a 75 dias de idade, de 0,0481 para 0,0229 e 0,0402 para $0,0327 \mathrm{~h}^{-1}$, respectivamente, para o capim adubado e não-adubado. Os respectivos decréscimos nas taxas de degradação da fibra em detergente neutro foram de 0,0447 para 0,0231 e 0,0357 para 0,0232 .
As taxas de degradação da proteína bruta decresceram, no período de 15 a 60 dias de idade, de 0,0454 para 0,0307 e de 0,0419 para 0,0274 , respectivamente, para o capim adubado e não-adubado.

\section{Referências Bibliográficas}

AFRC. 1993. Energy and Protein Requirements of Ruminants. An advisory manual prepared by the AFRC Technical Committee on Responses to Nutrients. CAB International, Wallingford, UK. $151 \mathrm{p}$.

ARMSTRONG, D.C. 1982. Digestion and utilizacion of energy In: INTERNATIONAL SYMPOSIUM OF NUTRITIONAL LIMISTS TO ANIMAL PRODUCTION FROM PASTURES, 1, Brisbane, 1981. Proceedings... Farnham Royal, CAB, p.225-44.

BALSALOBRE, M.A. A., CORSI, M., SANTOS, P.M. Avaliação de digestibilidade "in situ" de amostras simulando o pastejo em capim-elefante (Pennisetum purpureum Schum). 
Rev. bras. zootec.

In: REUNIÃO ANUAL DA SOCIEDADE BRASILEIRA DE ZOOTECNIA, 33, Fortaleza, CE, 1996. Anais... Fortaleza: SBZ, p.274-276, 1996.

BARBI, J.H.T. Avaliação da Degradabilidade Ruminal de Quatro Gramineas Tropicais em Diferentes Idades de Corte Pela Técnica "in situ". Belo Horizonte: UFMG, 1991. 61p Dissertação (Mestrado em Zootecnia) - Universidade Federal de Belo Horizonte, 1991.

BERAMASCHINE, A .F.., DUARTE, E.F., OKUDA, H.T. Degradabilidade "In Situ" de Gramíneas Tropicais. In: REUNIÃO ANUAL DA SOCIEDADE BRASILEIRA DE ZOOTECNIA, 31, Maringá, PR, 1994. Anais...Maringá: SBZ, 1994, p.700.

GOMES, B.V. Influência das características químicas e físicas das forragens sobre o consumo, degradação e cinética da digestão ruminal. Viçosa, MG: UFV, 1991. 106p. Tese (Doutorado em Zootecnia) - Universidade Federal de Viçosa, 1991.

MALAFAIA, P.A.M., VALADARES FILHO, S.C., COELHO DA SILVA, J. F. 1997. Determinação e Cinética das Frações Protéicas de Alguns Alimentos para Ruminantes. R. Bras. Zootec., 27:790-796.

MEHERZ, A.Z., ØRSKOV, E. R. A. 1977. Study of the Artificial Fibre Bag Techinique for Determining the Digestibility of Feeds in the Rumen. J. Agric. Sci., 88(3):645-650.

ØRSKOV, E.R., McDONALD, I. 1979. The estimation of protein degradability in the rumen from incubation measurements weighted according to rate of passage. J. Agric. Sci., 92(4):499-503.

RIBEIRO, H.M.N., OSPINA, H.P., APEZTEGUIA, E. et al. Degradabilidade Ruminal em Búfalos de Três Gramíneas Nativas do Rio Grande do Sul; In: REUNIÃO ANUAL DA SOCIEDADE BRASILEIRA DE ZOOTECNIA, 31, Maringá, PR, 1994. Anais...Maringá: SBZ, 1994, p.520.

SAS. Statistical Analysis System, 1989. SAS Institute, Cary, NC, USA. 207p.

SILVA, D.J. 1990. Análise de alimentos (métodos químicos e biológicos). 2 ed . Viçosa, MG: UFV. 165p.

SINGH, S.S.N. B., MAKKAR, P.P.S. 1989. Influence of method of calculation and length of period of rumen fermentation on the effective degradability of dry matter and nitrogen in some tree forages. Anim. Feed Sci. Tech., 26:309-322.
TEIXEIRA, J.C., BARBOSA, A.C., REIS, S.T. et al. Seqüência e tempo de incubação de sacos de náilon no rúmen afetando estimativa da degradabilidade ruminal da matéria seca, proteína bruta e fibra em detergente neutro. In: REUNIÃO ANUAL DA SOCIEDADE BRASILEIRA DE ZOOTECNIA, 33, Fortaleza, CE, 1996. Anais... Fortaleza: SBZ, 1996, p.362-364.

UDÉN, P., COLLUCCI, P.E., VAN SOEST, P. J. 1980. Investigation of chromium, cerium and cobalt as markers in digesta. Rate of passage studies. J. Sci. Food Agric., 31(6):625-632.

VAN SOEST, P.J. 1967. Development of a comprehensive system of feed analyses and its aplication to forages. J. Anim. Sci., 26(1):119-128.

VIEIRA, R.A.M., PEREIRA, J.C., QUEIROZ, A.C. et al. Estimativa da digestibilidade ruminal do capim-elefante a partir de ensaios de degradação in situ e in vitro. In: REUNIÃO ANUAL DA SOCIEDADE BRASILEIRA DE ZOOTECNIA, 33, Fortaleza, CE, 1996. Anais... Fortaleza: SBZ, 1996, p.297-299.

VILELA, G.L. Degradabilidade "in situ" da matéria seca e da proteina bruta de vários alimentos em vacas alimentadas com diferentes rações. Viçosa, MG: UFV, 1994. 62p. Dissertação (Mestrado em Zootecnia) - Universidade Federal de Viçosa, 1994.

Recebido em: 20/03/98

Aceito em: 03/02/99 